\title{
Study of Symptoms, Risk Factors and Prescribing Patterns in Cerebral Stroke Patients
}

\author{
Sridhar Srimath Tirumala Konduru*, Amit Ranjan, Jyothi Sri Nallajerla, Sravya Gonuguntala
}

Department of Pharmacy Practice, Shri Vishnu College of Pharmacy, Bhimavaram, Andhra Pradesh, INDIA

\begin{abstract}
A prospective observational study was conducted at Bhimavaram hospitals Bhimavaram, to assess the symptoms, risk factors and prescribing patterns in cerebral stroke patients. A total of 80 patients of age group $20-90$ (mean age 63.1) were considered in the study which includes both the genders. These patients were assessed regarding their demographics, symptoms, risk factors and prescribing patterns. The incidence of stroke was higher in males (70\%) compared to females (30\%). Out of these study population $85 \%$ experienced Ischemic stroke, $11 \%$ Transient ischemic attack (TIA) and 4\% Hemorrhagic stroke. These patients presented weakness as common symptom, Hypertension as prominent risk factor and anti-platelet agents as commonly prescribed drugs. Early management of Hypertension and Diabetes may reduce the risk of stroke. Our study suggests that life style changes play a key role in prevention of stroke.
\end{abstract}

Key words: Hypertension, Transient Ischemic Attack, Hemorrhagic Stroke, Ischemic Stroke, risk factors, life style.

\section{INTRODUCTION}

Stroke or Cerebrovascular accident is an acute focal neurologic deficit that lasts for 24hours due to disturbances in cerebral blood flow. ${ }^{6,20} \mathrm{It}$ is a medical emergency which occurs commonly in elderly patients. It is a major cause of mortality worldwide. ${ }^{2,7,19} \mathrm{It}$ is the leading cause of death only next to cancer. ${ }^{11,29,33}$

There are three types of strokes, which include

Ischemic $(88 \%)$

Hemorrhagic $(12 \%)$ and

Transient (rare type). ${ }^{6,8,18}$

According to WHO, 15 million people worldwide suffer from stroke each year. ${ }^{6}$ In India incidence of stroke is 145/100,000 per year during $2003-06 .{ }^{7,10}$ One in six people suffer from stroke in their life time. ${ }^{21}$ The mortality rate due to stroke in India is 22 times that of malaria and 1.4times that of Tuberculosis. ${ }^{3,4,7}$ Approximately $\quad 780,000$ new and recurrent strokes occur annually in the US. ${ }^{22}$ This change in population demographics result in increased demands on health services as stroke affects severe functional loss in elderly people. ${ }^{2}$

Risk factors can be classified as nonmodifiable and modifiable. For example, non-modifiable risk factors are advanced age, males and family history of stroke. Modifiable risk factors are hypertension, smoking, obesity, heavy drinking (alcoholism), Atrial fibrillation, elevated cholesterol levels, physical inactivity and carotid stenosis. ${ }^{12,13,24}$ The common risk factors include diabetes, ${ }^{17}$ hypertension, ${ }^{25}$ smoking, and obesity. $^{2}$ Cigarette smoking is a significant risk factor for all forms of stroke. ${ }^{23}$ Incidence of stroke increases with advancing age. ${ }^{16}$ Previoushistory of stroke is a major risk factor for recurrent ischemic stroke. ${ }^{11}$ Hypertension plays a major role in the risk of both ischemic stroke and intracranial hemorrhage. Diabetes mellitus triples the risk while cigarette smoking doubles it. An important risk factor for stroke is atrial fibrillation which is often asymptomatic. ${ }^{5}$

Morbidity and mortality related to Ischemic stroke can be counteracted by its
DOI: 10.5530ijopp.10.1.6

Address for correspondence: Dr. Sridhar Srimath Tirumala Konduru,

Assistant Professor, Department of Pharmacy Practice, Shri Vishnu College of pharmacy, Andhra Pradesh, INDIA

Phone no: 9642880200 E-mail: sridharstk@gmail.com 
prevention. $50 \%$ of stroke is preventable by control of modifiable risk factors and lifestyle changes (aerobic exercise to counteract inactivity, weight loss in obesity, glucose control in diabetics, smoking cessation, and diet., ${ }^{5,14}$ American Stroke Association (ASA) and the American Heart Association (AHA) have recently published updated guidelines for secondary prevention of stroke. ${ }^{5,20}$ Framingham Stroke Risk Profile (FSRP) have been developed, which provides an illustration for patient education that are easy to use in clinical practice. $^{22}$

The present study aims to provide a comprehensive review on gender differences in stroke, with specific stress on the demographics, risk factors, symptoms, prescription pattern and duration of hospital stay. The objective of this study is to work out about the symptoms, risk factors and assessment of the prescribing patterns of neuro physicians to identify the choice of one drug over the other and about the changes made when stroke occurs in patient. $^{2}$

\section{METHODOLOGY}

\section{Study Site}

This study was conducted in In-Patient set up of Neurology Department at Bhimavaram Hospital, Bhimavaram, and Andhra Pradesh. It is a 300 bedded multispecialty tertiary care teaching hospital.

\section{Inclusion Criteria}

Male and female patients of age 20 years and above were included in the study.

Patients diagnosed with Ischemic, Hemorrhagic stroke and TIA was included in the study.

\section{SAMPLE SIZE}

After Patient admission, 100 patients were selected out of them 80 gave positive response.

\section{STATISTICAL ANALYSIS}

Mean, Standard Deviation

\begin{tabular}{ccc}
\hline \multicolumn{3}{c}{ Table 1: Age group categorization of stroke patients } \\
\hline AGE & NO OF PATIENTS & PERCENTAGE (\%) \\
\hline $21-30$ & 01 & $01 \%$ \\
$31-40$ & 02 & $02 \%$ \\
$41-50$ & 10 & $13 \%$ \\
$51-60$ & 24 & $30 \%$ \\
$61-70$ & 24 & $30 \%$ \\
$71-80$ & 13 & $16 \%$ \\
$81-90$ & 06 & $08 \%$
\end{tabular}

The Parameters monitored were entered in Microsoft Excel 2007 and applied Descriptive Statistics for each variables included in the Data Collection Form. Mean and SD values were calculated by using SAS 9.3 Version. The Tables and Graphs were drawn for each variable in data collection form and also calculated percentages for each variable.

\section{ETHICAL CONSIDERATION}

The study was carried out from January 2016 to June 2016 after due permission from the Institutional Ethics Committee and after getting consent (in written form) from all the participating subjects.

\section{RESULTS AND DISCUSSION}

\section{Results}

Table and Figure -1: Represents Age Group Categorization of Stroke Patients.

Table and Figure-2: Represents Gender wise Characterization of Stroke Patients

Table and Figure-3: Represents Type Wise Characterization of Stroke Patients

Table and Figure-4: Represents Pattern of Symptoms in Stroke Patients

Table and Figures-5: Represents Pattern of Risk Factors among Stroke Patients

Table and Figure-6: Represents Pattern of Drugs in Stroke Patients According To Their Class

Table and Figure-7: Represents Pattern of Drugs in Stroke Patients according To Their Frequency

Table and Figure-8: Represents Single Vs. Combination Therapy.

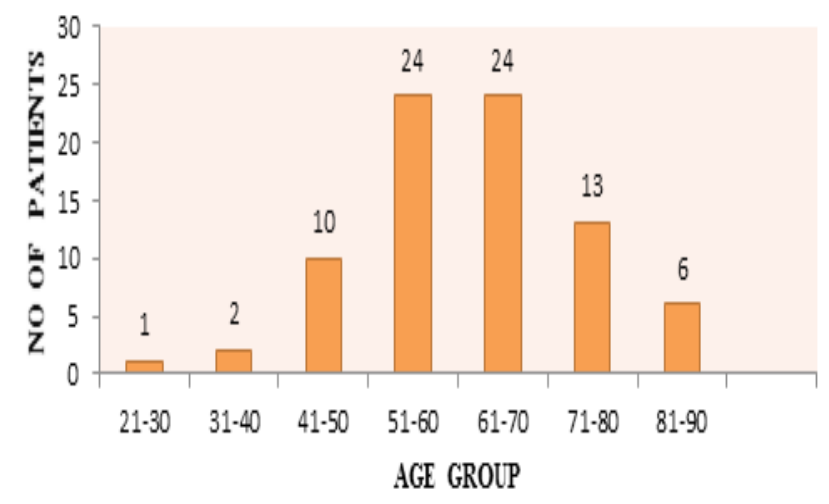

Figure 1: Age group categorization of stroke patients. 
Table 2: Data obtained about patient demographic characters (Gender)

\begin{tabular}{ccc}
\hline GENDER & NO OF PATIENTS & PERCENTAGE (\%) \\
\hline Males & 56 & $70 \%$ \\
Females & 24 & $30 \%$
\end{tabular}

\begin{tabular}{ccc|}
$\begin{array}{l}\text { Table 3: Type wise categorization of stroke according } \\
\text { to their frequency }\end{array}$ & NO OF PATIENTS & $\begin{array}{c}\text { PERCENTAGE } \\
\text { (\%) }\end{array}$ \\
\hline TYPE OF STROKE & & 85 \\
\hline Ischemic stroke & 68 & 4 \\
Hemorrhagic stroke & 3 & 11 \\
TIA & 9 & \\
\hline
\end{tabular}

\begin{tabular}{|c|c|c|c|}
\hline S.NO & SYMPTOMS & $\begin{array}{c}\text { NO OF } \\
\text { PATIENTS }\end{array}$ & $\begin{array}{c}\text { PERCENTAGE } \\
(\%)\end{array}$ \\
\hline 1 & $\begin{array}{l}\text { Weakness of Upper } \\
\qquad \operatorname{limb}\end{array}$ & 56 & $18 \%$ \\
\hline 2 & Dysarthria & 49 & $16 \%$ \\
\hline 3 & $\begin{array}{l}\text { Weakness of lower } \\
\text { limb }\end{array}$ & 36 & $12 \%$ \\
\hline 4 & Left hemi paresis & 35 & $11 \%$ \\
\hline 5 & Right hemi paresis & 32 & $11 \%$ \\
\hline 6 & Facial palsy & 22 & $7 \%$ \\
\hline 7 & Giddiness & 15 & $5 \%$ \\
\hline 8 & Aphasia & 11 & $4 \%$ \\
\hline 9 & Tingling sensation & 10 & $3 \%$ \\
\hline 10 & Deviation of mouth & 9 & $3 \%$ \\
\hline 11 & Headache & 9 & $3 \%$ \\
\hline 12 & Dyskinesia & 8 & $3 \%$ \\
\hline 13 & Altered sensorium & 7 & $2 \%$ \\
\hline 14 & Ataxia & 6 & $2 \%$ \\
\hline
\end{tabular}

\begin{tabular}{cccc}
\hline Table 5: Pattern of Risk factors among Stroke patients \\
\hline S .NO & RISK FACTORS & $\begin{array}{c}\text { NO OF } \\
\text { PATIENTS }\end{array}$ & $\begin{array}{c}\text { PERCENTAGE } \\
\text { (\%) }\end{array}$ \\
\hline 1 & Hypertension & 49 & $27 \%$ \\
2 & Diabetes & 46 & $25 \%$ \\
3 & Alcohol & 21 & $12 \%$ \\
4 & Smoking & 19 & $10 \%$ \\
5 & Recurrent stroke & 19 & $10 \%$ \\
6 & Hyperlipidemia & 11 & $6 \%$ \\
7 & Coronary artery & 9 & $5 \%$ \\
8 & disease & & \\
8 & Chronic kidney & 5 & $3 \%$ \\
9 & disease & & 15 \\
10 & Head injury & 2 & $1 \%$ \\
\end{tabular}

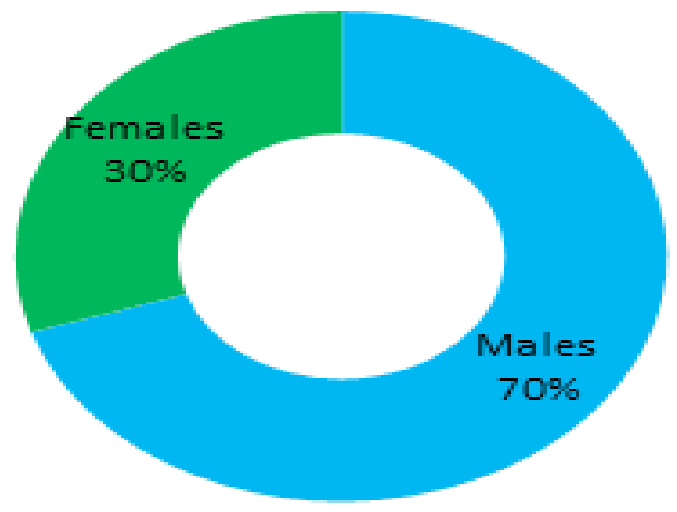

Figure 2: Data obtained about patient demographic characters (Gender).

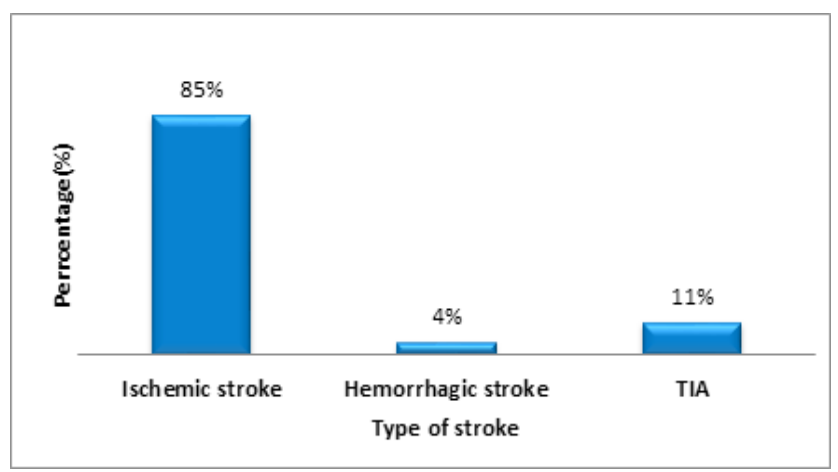

Figure 3: Type wise categorization of stroke according to their frequency.

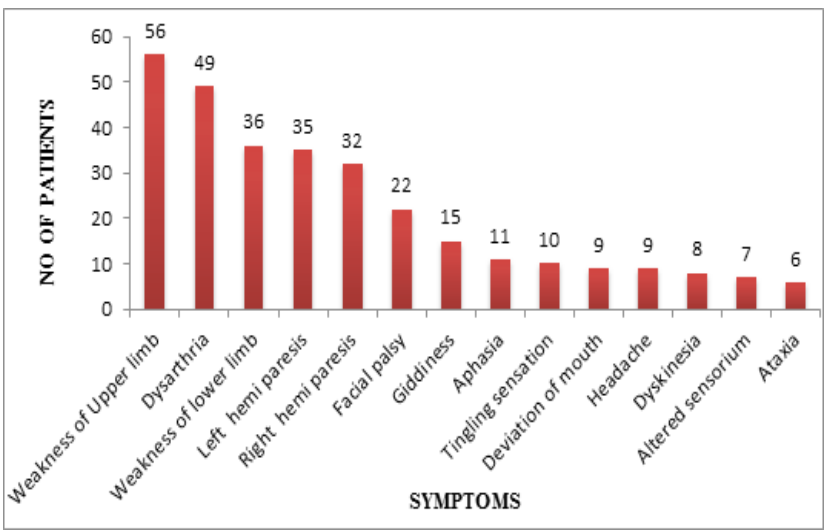

Figure 4: Pattern of Symptoms among Stroke patients.

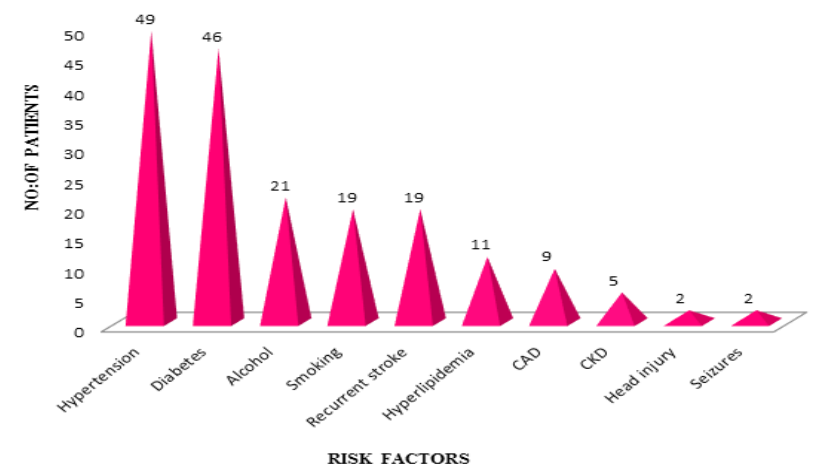

Figure 5: Pattern of Risk factors among Stroke patients.

Indian Journal of Pharmacy Practice, Vol 10, Issue 1, Jan-Mar, 2017 


\begin{tabular}{ccc}
$\begin{array}{l}\text { Table 6: Pattern of drugs in stroke patients according } \\
\text { to their class }\end{array}$ & $\begin{array}{c}\text { NO OF } \\
\text { PATIENTS }\end{array}$ & PERCENTAGE (\%) \\
\hline Anticoagulants & 36 & $10 \%$ \\
Antiplatelets & 89 & $25 \%$ \\
Dyslipidemics & 66 & $19 \%$ \\
Anticonvulsants & 32 & $9 \%$ \\
Psycho stimulants & 71 & $20 \%$ \\
Beta-blockers & 04 & $1 \%$ \\
Calcium Channel & 15 & $4 \%$ \\
Blockers & & $6 \%$ \\
Angiotensin Receptor & 23 & \\
Blockers & 16 & $5 \%$ \\
Osmotic diuretics & 16 & $1 \%$ \\
Vasodilators & 3 & $1 \%$ \\
Central alpha 2 agonist & 1 & \\
Potassium sparing & 1 & \\
diuretics & 1 & \\
Mixed blocker & & \\
& &
\end{tabular}

Table 7: Pattern of Drugs in Stroke patients according to their frequency

\begin{tabular}{ccc}
\hline DRUG & NO OF PATIENTS & PERCENTAGE (\%) \\
\hline Clopidogrel & 70 & $21 \%$ \\
Citicoline & 67 & $20 \%$ \\
Atorvastatin & 56 & $16 \%$ \\
Enoxaparin & 34 & $10 \%$ \\
Aspirin & 19 & $6 \%$ \\
Mannitol & 16 & $5 \%$ \\
Amlodipine & 13 & $4 \%$ \\
Losartan & 13 & $4 \%$ \\
Levitiracetam & 9 & $3 \%$ \\
Telmisartan & 9 & $3 \%$ \\
Fenofibrate & 8 & $2 \%$ \\
Divalproex sodium & 7 & $2 \%$ \\
Lonazepam & 6 & $2 \%$ \\
Gabapentin & 5 & 15 \\
Metaprolol & 3 & $1 \%$ \\
Glyceryltrinitrite & 3 & $1 \%$ \\
Phenytoin & 2 & $1 \%$
\end{tabular}

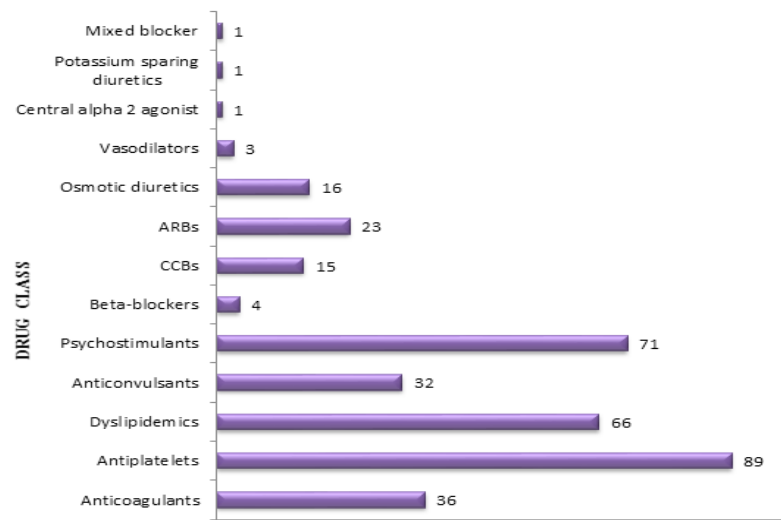

Figure 6: Pattern of drugs in stroke patients according to their class.

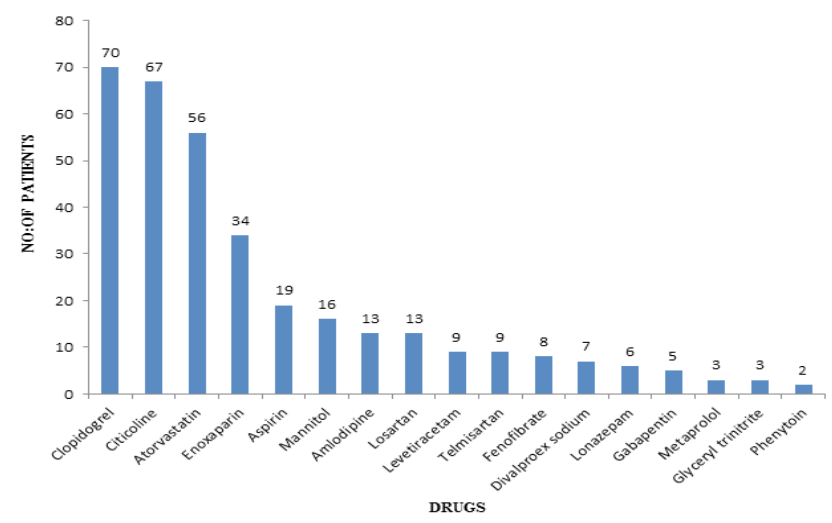

Figure 7: Pattern of Single Drugs in Stroke patients according to their frequency.

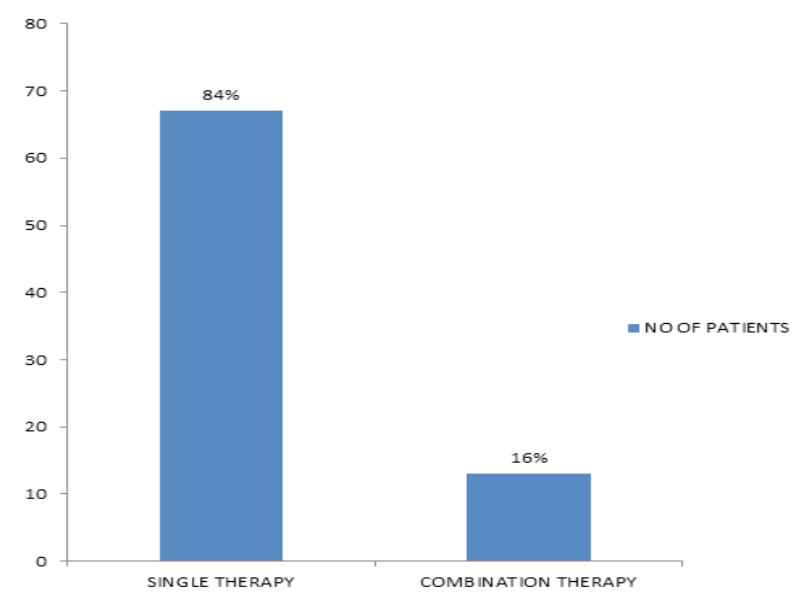

Figure 8: Single Vs Combination therapy.

\begin{tabular}{|cccc}
\hline \multicolumn{4}{c}{ Table 8: Single vs Combination therapy } \\
\hline S.NO & $\begin{array}{c}\text { TYPE OF } \\
\text { THERAPY }\end{array}$ & $\begin{array}{c}\text { NO OF } \\
\text { PATIENTS }\end{array}$ & $\begin{array}{c}\text { PERCENTAGE } \\
\text { (\%) }\end{array}$ \\
\hline 1 & $\begin{array}{c}\text { SINGLE } \\
\text { THERAPY }\end{array}$ & 67 & $84 \%$ \\
2 & $\begin{array}{c}\text { COMBINATION } \\
\text { THERAPY }\end{array}$ & 13 & $16 \%$ \\
\hline
\end{tabular}




\begin{tabular}{|c|c|c|c|c|c|c|c|}
\hline \multicolumn{8}{|c|}{ OVERVIEW OF STUDY } \\
\hline \multirow{2}{*}{$\begin{array}{l}\text { AGE } \\
\text { GROUP }\end{array}$} & \multirow{2}{*}{$\begin{array}{c}\text { NO OF } \\
\text { PATIENTS }\end{array}$} & \multirow{2}{*}{$\begin{array}{l}\text { NO OF SYMPTOMS } \\
\text { (MEAN) }\end{array}$} & \multirow{2}{*}{$\begin{array}{l}\text { NO OF RISK FACTORS } \\
\text { (MEAN) }\end{array}$} & \multicolumn{3}{|c|}{ TYPE OF STROKE } & \multirow{2}{*}{$\begin{array}{l}\text { NO OF DRUGS } \\
\text { (MEAN) }\end{array}$} \\
\hline & & & & ISCHEMIC & TIA & HEMORRHAGIC & \\
\hline $21-30$ & 1 & 3 & 3 & 1 & 0 & 0 & 3 \\
\hline $31-40$ & 2 & 5 & 0 & 2 & 0 & 0 & 4 \\
\hline $41-50$ & 10 & 4 & 5 & 8 & 1 & 1 & 5 \\
\hline $51-60$ & 24 & 4 & 4 & 18 & 5 & 1 & 5 \\
\hline $61-70$ & 24 & 5 & 5 & 22 & 1 & 1 & 5 \\
\hline $71-80$ & 13 & 5 & 4 & 11 & 2 & 0 & 6 \\
\hline $81-90$ & 6 & 3 & 6 & 6 & 0 & 0 & 4 \\
\hline
\end{tabular}

\section{DISCUSSION}

The incidence of stroke is maximum in the age group around 50-70 years which comprised of $60 \%$ of the patients followed by the age group 71-80 which comprised of $16 \%$ of an entire study population because of more no of risk factors like chronic diseases (Hypertension, DM).

The incidence of stroke was high in Males $(70 \%)$ than in females $(30 \%)$ which can be attributed to-

a. Estradiol has terribly potent effects on endothelia that promote dilation of blood vessels and blood flow, whereas testosterone has opposite effects. This indicates women are protected by endogenous estrogens.

b. Males are more prone to HTN and DM than females c. Smoking

Out of the total study population, 68 patients i.e., $(85 \%)$ experienced Ischemic stroke, 9 patients i.e., (11\%) experienced TIA and 3 patients i.e., (4\%) experienced Hemorrhagic stroke. This suggests that ischemic stroke is more prevalent than the rest two due to pathophysiological changes in blood supply to brain.

Males are more prone to Ischemic stroke and TIA than females because of smoking, which leads to free radical formation that reduces oxygen supply.

Decreased blood supply to the brain is the major cause of stroke in all age groups and gender, therefore Ischemic stroke was highest followed by TIA and Hemorrhagic stroke.

Out of total patients $(\mathrm{N}=80), 18 \%$ patients presented with symptoms like Weakness of upper limb, 16\% with dysarthria, 12\% with weakness of lower limb followed by left and right hemi paresis in 11\%, Facial palsy in $7 \%$, giddiness in $5 \%$, aphasia in $4 \%$, tingling sensation, deviation of mouth and dyskinesia in $(3 \%)$, altered sensorium and ataxia in $2 \%$ of patients.

Among 80 patients, the most common risk factors associated with stroke were hypertension in $27 \%$ patients followed by Diabetes in 25\%, Alcohol in 12\%, Smoking and recurrent stroke in 10\%, Hyperlipidemia in 6\%, $\mathrm{CAD}$ in $5 \%, \mathrm{CKD}$ in $3 \%$, Head injury and seizures in $1 \%$ of patients.

The most common class of drugs prescribed were antiplatelets, psycho stimulants, antihypertensive, dyslipidemics, anticoagulants and anticonvulsants in the number $89,71,64,66,36$ and 32 patients respectively.

The most frequently used drugs were-

Antiplatelet (Clopidogrel)-70

Psycostimulant (Citicoline) - 67

Dyslipidemic (Atorvastatin) - 56

Most commonly used combination therapy in this study was REMETOR (Atorvastatin+Clopidogrel)

The total no of patients who were prescribed with single drug therapy are 67 i.e., (84\%) and with combination therapy are 13 i.e., (16\%).

The data of the study could helpful in risk factor avoidance and provides appropriate medical therapy in these patients.

\section{CONCLUSION}

Out of total 80 patients, the maximum number of cases were in age group 50-70years. The incidence of stroke was high in males than females in which Ischemic stroke was more prevalent than Hemorrhagic and TIA. The most commonly seen symptom was Hemiparesis followed by dysarthria. Hypertension and Diabetes were the most common risk factors and the frequently prescribed class of drugs were Antiplatelets followed by Psychostimulants in Which clopidogrel and citicoline were respectively.

Our study suggests life style changes for prevention of cerebral stroke, which include:

Control high Blood pressure, DM and lipids.

Avoid alcohol 
Quit smoking; avoid passive smoking and exposure to air pollution.

Control over weight

Manage stress and Regular exercise

Have regular check up with physician.

Pharmacists are in an ideal position to review the patient's risk factors for stroke and to initiate or recommend appropriate pharmacotherapy where indicated. Therefore the integration of the role of pharmacist in the management of stroke is very crucial and improves outcomes of the patients.

\section{ACKNOWLEDGEMENT}

We thank Dr. shivaranjani and Dr N.Pratyusha for their support.

\section{ABBREVIATIONS}

HTN: Hypertension; DM: Diabetes Mellitus; COPD: Chronic Obstructive Pulmonary Disease; ; CAD: Coronary Artery Disease; CKD: Chronic: Kidney Disease; DVT: Deep Vein Thrombosis; UTI: Urinary Tract Infection; CVA: Cerebro Vascular Accident; ACA: Anterior Cerebral Artery; PCA: Posterior Cerebral Artery; MCA: Middle Cerebral Artery; BPH: Benign Prostate Hyperplasia; CLD: Chronic Liver Disease; NSTEMI: Non St-Elevation Myocardial Infarction; AF: Atrial Fibrillation; TIA: Transient Ischemic Attack; IMT: Inflammatory Myofibroblastic Tumour; ICMP: Ischemic Cardio Myopathy; DTR: Deep Tendon Reflex; LV: Left Ventricle; Dysfunction; GCS: Glasgow Coma Scale; SOB: Shortness Of Breath; GRBS: General Random Blood Sugar; PTCA: Percutaneous Transluminal Coronary Angioplasty; FLAIR: Fluid Attenuated Inversion Recovery; EOM: Extra Occular Muscles; MVP: Mitral Valve Prolapse; MRI: Magnetic Resonance Imaging; RF: Risk Factor; CG: Chorionic Gonadotropin; IC: Intra Cerebral; FVR: Fast Ventricular Rate; CABG: Coronary: Artery Bypass Graft; ECG: Electro Cardiogram; USG: Ultra Sonogram; CT: Computated Tomography; PAH: Pulmonary Arterial Hypertension

\section{CONFLICT OF INTEREST}

No conflicts of interest

\section{REFERENCES}

1. Brewer L, Horgan F, Hickey A, Williams D. Stroke rehabilitation: recent advances and future therapies. QJM. 2012:hcs174. PMid:23019591.
2. Preethi PB, Naveed A, Shreya S, Sri Lakshmi G, Rao V. Prescribing pattern of drugs in stroke patients admitted to a multi speciality hospital, india.

3. Lecouturier J, Rodgers H, Murtagh MJ, White M, Ford GA, Thomson RG. Systematic review of mass media interventions designed to improve public recognition of stroke symptoms, emergency response and early treatment. BMC Public Health. 2010;10(1):784.http://dx.doi.org/10.1186/1471-2458-10784 ; PMid:21182777 PMCid:PMC3022856.

4. Vurumadla S, Rakshith V, Ch M, Venkateswarlu K. A study on symptoms, risk factors and prescribing pattern of drugs used in stroke patients. International Journal of Pharmacy and Pharmaceutical Sciences. 2014;7(1):421-6.

5. Di Legge S, Koch G, Diomedi M, Stanzione P, Sallustio F. Stroke prevention: managing modifiable risk factors. Stroke research and treatment. $2012 \mathrm{Nov}$ 4.http://dx.doi.org/10.1155/2012/391538 ; PMCid:PMC3504482.

6. Sangam S, Naveed A, Athar M, Prathyusha P, Moulika S, Lakshmi S. A Study on Functional Measures in Patients with Stroke. International Journal of Health Sciences and Research (IJHSR). 2015;5(1):156-64.

7. Abbasi MY, Ali MA. Prescribing pattern of drugs in stroke patients: A prospective study. Archives of Pharmacy Practice. 2012;3(4):283. http://dx.doi. org/10.4103/2045-080X.106253.

8. Harrington C. Managing Hypertension in Patients With Stroke Are You Prepared for Labetalol Infusion?. Critical Care Nurse. 2003;23(3):30-8. PMid:12830778.

9. Davis S, Lees K, Donnan G. Treating the acute stroke patient as an emergency: current practices and future opportunities. International Journal of Clinical Practice. 2006;60(4):399-407 http://dx.doi.org/10.1111/j.13685031.2006.00873.x ; PMid:16620351 PMCid:PMC1448697.

10. Pandian JD, Sudhan P. Stroke epidemiology and stroke care services in India. J Stroke. 2013;15(3):128-34. http://dx.doi.org/10.5853/jos.2013.15.3.128 ; PMid:24396806 PMCid:PMC3859004

11. Bushnell CD, Colón-Emeric CS. Secondary Stroke Prevention Strategies for the Oldest Patients. Drugs andAging. 2009;26(3):209-30. http://dx.doi. org/10.2165/00002512-200926030-00003 ; PMid:19358617

12. Hegelhle-Hansen.MD, Bente T, Torgeir BW,MD, Knut E,MD, and Brynjar F, MD, The Lancet Neurology. Funct Neurology .1991;337(8756):1521-6.

13. Skånér $Y$, Nilsson GH, Krakau I, Hassler E, Sundquist K. Primary prevention of first-ever stroke in primary health care: a clinical practice study based on medical register data in Sweden. Stroke research and treatment. 2010; 2010.

14. Bijoy K.Menon, MD; Michael R.Frankel, MD; Li Liang, PhD et al, Guidelines for the Early Management of Patients With Acute Ischemic Stroke: 2010;41:20942097.

15. Jauch EC, Saver JL, Adams HP, Bruno A, Demaerschalk BM, Khatri P, et al, Guidelines for the early management of patients with acute ischemic stroke a guideline for healthcare professionals from the American Heart Association/ American Stroke Association. Stroke. 2013;44(3):870-947. http://dx.doi. org/10.1161/STR.0b013e318284056aPMid:23370205.

16. Myint PK, Staufenberg EF, Sabanathan K. Post-stroke seizure and post-stroke epilepsy. Postgraduate Medical Journal. 2006;82(971):568-72. http://dx.doi. org/10.1136/pgmj.2005.041426 ; PMid:16954451 PMCid:PMC2585721.

17. Kissela BM, Khoury J, Kleindorfer D, Woo D, Schneider A, Alwell K, et al. Epidemiology of Ischemic Stroke in Patients With Diabetes The Greater Cincinnati/Northern Kentucky Stroke Study. Diabetes care. 2005;28(2):355-9. http://dx.doi.org/10.2337/diacare.28.2.355; PMid:15677792.

18. Ovbiagele B, Nguyen-Huynh MN. Stroke epidemiology: advancing our understanding of disease mechanism and therapy. Neurotherapeutics. 2011;8(3):319. http://dx.doi.org/10.1007/s13311-011-0053-1 ; PMid:21691873 PMCid:PMC3250269.

19. Fahimfar N, Khalili D, Mohebi R, Azizi F, Hadaegh F. Risk factors for ischemic stroke; results from 9 years of follow-up in a population based cohort of Iran. BMC Neurology. 2012;12(1):1. http://dx.doi.org/10.1186/1471-2377-12-117 ; PMid:23031547 PMCid:PMC3517457.

20. Sun JH, Tan L, Yu JT. Post-stroke cognitive impairment: epidemiology, mechanisms and management. Annals of Translational Medicine. 2014;2(8).

21. Sudheer k.Hypertenstion and ischemic stroke.Hypertens J. 2016;2(1):39-43. http://dx.doi.org/10.5005/jp-journals-10043-0028.

22. Romero JR, Morris J, Pikula A. Review: Stroke prevention: modifying risk factors. Therapeutic Advances in Cardiovascular Disease. 2008;2(4):287303. http://dx.doi.org/10.1177/1753944708093847 ; PMid:19124428 PMCid:PMC2729177. 
23. Shah RS, Cole JW. Smoking and stroke: the more you smoke the more you stroke. Expert review of cardiovascular therapy. 2010;8(7):917-32. http://dx.doi. org/10.1586/erc.10.56 ; PMid:20602553 PMCid:PMC2928253.

24. Wolf PA, Clagett GP, Easton JD, Goldstein LB, Gorelick PB, Kelly-Hayes M, et al. Preventing ischemic stroke in patients with prior stroke and transient ischemic attack a statement for healthcare professionals from the Stroke
Council of the American Heart Association. Stroke. 1999;30(9):1991-4. http:// dx.doi.org/10.1161/01.STR.30.9.1991; PMid:10471455.

25. ladecola C, Gorelick PB. Hypertension, angiotensin, and stroke.Beyond Blood Pressure. Stroke. 2004;35(2):348-50. http://dx.doi.org/10.1161/01. STR.0000115162.16321.AA; PMid:14757875. 